\title{
Frutas: Practicas de Cuidado de Manejo para los Consumidores $^{1}$
}

Amy Simonne ${ }^{2}$

Comer una variedad de frutas y vegetales es un parte de una buena dieta saludable. Sin embargo, tiene que evitar que estos se contaminen durante el proceso de preparación, estos pueden contener enfermedades como la de contaminación de alimentos (foodborne) que han sido encontrados en productos frescos. Las frutas que vienen de árboles frutales encontrados en zonas templadas. Estas frutas de incluyen: peras, manzanas, melocotones, cerezas, nectarinos, duraznos, y ciruelas. Aquí hay algunos pasos para reducir el riesgo de contaminación de alimentos fuera de los productos frescos.

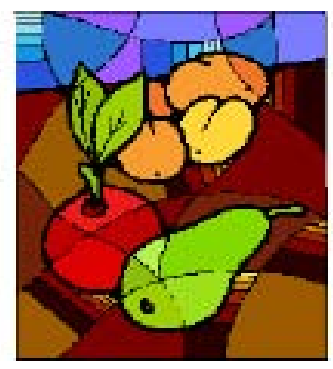

\section{Donde Comprar:}

Compre solamente frutas que este en buen estado y que no estén golpeadas.

Los cortes de fruta fresca deben estar bien refrigerados y con hielo encima.

\section{En Casa:}

Refrigere la fruta que esta pelada lo más pronto posible. Para un sabor optimo, algunas frutas como los duraznos se pueden dejar al clima cuando estén pelados por un rato antes de refrigerarlos.
Refrigere los cortes frescos de fruta entre dos horas de haber sido la fruta pelada o cortada.

Arroje los sobrados de fruta después de dos horas que hayan sido cortada.

\section{Durante la Preparación:}

Lave sus manos con agua tibia y jabón antes y después:

- Manejar productos frescos

- Manejar carne cruda, pollo, o comida de mar

- Usar el baño

- Cambiar pañales

- Tocar una mascota

1. Este documento, FCS8742-Span, es uno de una serie del Departamento de Ciencias de la Familia, Juventud y Comunidad, del Servicio de Extensión Cooperativa de Florida, Instituto de Alimentos y Ciencias Agrícolas, Universidad de Florida. Fecha de publicación: Noviembre 2002. Revisado: Marzo 2006. Traducido Junio 2007 al español por Marcela Lacayo y Samara Vasquez. Favor visite el sitio Web EDIS en http://edis.ifas.ufl.edu.

2. Amy Simonne, Professor Asociado en Familia, Juventud y Ciencias en Comunidades, Instituto de Alimentos y Agricultura Ciencias, Universidad de Florida, Gainesville 32611.

El Instituto de Alimentos y Ciencias Agrícolas es un empleador que provee Oportunidades Igualitarias, autorizado a proveer investigación, información educativa y otros servicios, únicamente a los individuos e instituciones que operan sin discriminación alguna con relación al credo, color, religión, edad, incapacidad, sexo, orientación sexual, estado civil, nacionalidad, opinion política o afiliaciones. Para más información sobre como obtener otras publicaciones de extensión, comuníquese con la oficina de Servicio de Extensión de su condado. 
- Lave las frutas con un agua fría de la llave antes de prepáralos o comerlos. No use jabón ni detergentes.

Pele la fruta si es posible para reducir la contaminación de su superficie.

Friegue la fruta firmemente con un cepillo para alimentos que este limpio. Enjúguela bien con agua fría de la llave.

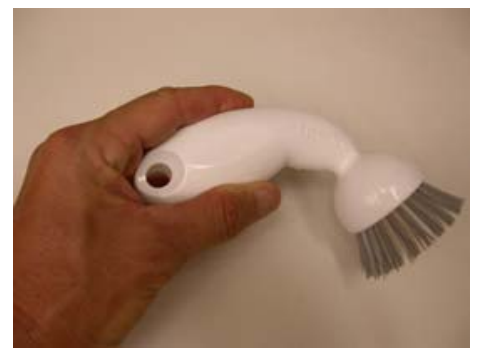

Remueva la semilla de la manzana

Remueva la semilla de la manzana y de la pera y enjuáguelas bien antes de cortarlas. Esto reducirá potencialmente la contaminación de microbios que se encuentran el centro de la fruta.

Corte las partes que estén negras o mal tratadas antes de prepáralas o comerlas.

Lave bien la tabla para cortar los alimentos, los platos, utensilios, y las superficies de la cocina frecuentemente. Use agua caliente con jabón y enjuáguelos bien. Desinféctelos después del contacto con productos frescos, o carne cruda, pollo, o comida de mar (vea la tabla).

Desinfecte el lava platos, las superficies de la cocina, y otros alimentos que estén en contacto con las superficies para prevenir la formación de microbios.

¡No cruce que contamina! Use tablas para cortar los alimentos y utensilios para los productos frescos.

- Si es posible, use una tabla para cortar separada de la carne cruda, el pollo, y la comida de mar.

No consuma hielo que ha tenido contacto con productos frescos o crudos.

Use un cooler con hielo o paquetes de gel congelado, cuando lleve alimentos frescos al aire libre.

\section{Para desinfectar las tablas para cortar los alimentos, y utensilios de comida:}

Mezcle una cucharadita blanqueador en un cuarto de agua.

Vacié la mezcla sobre las superficies o sumerja apropiadamente estos utensilios y déjelos entre la solución por lo menos por un minuto.

Enjuague las superficies bien con agua caliente.

Los gabinetes de la cocina, pueden ser desinfectados usando la solución anterior, desinfecte roseando o limpiando como una medida de seguridad adicional.

Una maquina para lavar platos con un ciclo de agua caliente (por lo menos $180^{\circ} \mathrm{F}$ o $82^{\circ} \mathrm{C}$ ) para un enjugue final, es también muy efectivo.

Siga estos pasos para reducir el riesgo de contaminación de alimentos (foodborne) que se encuentran en los productos frescos.

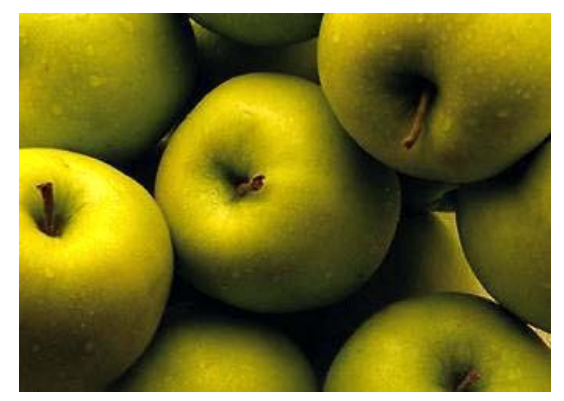

\section{Para Más Información:}

Visite la Administración de Alimentos y Drogas (FDA) página Web: http://www.fda.gov o llame a FDA Inquietud del Consumidor al 1-888SAFEFOOD (comida sana) (un numero gratuito). 